\title{
Perceptions of Dental Undergraduates Towards Online Education During COVID-19: Assessment from India, Nepal and Sri Lanka
}

\author{
Pragati Kaurani (D) \\ Kavita Batra (iD ${ }^{2}$ \\ Himangini Rathore Hooja (D) ${ }^{3}$ \\ Rajlakshmi Banerjee ${ }^{4}$ \\ Rasika Manori Jayasinghe ${ }^{5}$ \\ Dhanushka Leuke Bandara (iD) ${ }^{6}$ \\ Navin Agrawal iD ${ }^{7}$ \\ Vimmi Singh ${ }^{7}$ \\ 'Department of Prosthodontics Crown
} and Bridge, Mahatma Gandhi Dental College and Hospital, Jaipur, 302022, India; ${ }^{2}$ Office of Research, Kirk Kerkorian School of Medicine at University of Nevada, Las Vegas, Las Vegas, NV, 89102, USA; ${ }^{3}$ Department of Psychology, IIS

(Deemed to be University), Jaipur, 302020, Rajasthan, India; ${ }^{4}$ Department of Prosthodontics, VSPM Dental College and Research Centre, Nagpur, Maharashtra, 440019, India; ${ }^{5}$ Department of Prosthetic Dentistry, Faculty of Dental Sciences, University of Peradeniya, Peradeniya, 20400, Sri Lanka;

${ }^{6}$ Department of Oral Medicine and Periodontology, Faculty of Dental Sciences, University of Peradeniya, Peradeniya, 20400, Sri Lanka;

${ }^{7}$ Department of Conservative Dentistry, B.P. Koirala Institute of Health Sciences, Dharan, Nepal

Correspondence: Pragati Kaurani Mahatma Gandhi Dental College and Hospital, RIICO Industrial Area, Sitapura, Jaipur, 302022, India

Fax +9| |4|-2770326

Email drpragatikaurani@rediffmail.com
Purpose: The social distancing mandates instituted during COVID-19 pandemic mark the sudden transition in the mode of dental education's delivery to the virtual instruction. It is vital to assess students' perceptions towards virtual learning environments, particularly among those gaining education in resource-strained countries. This cross-sectional study aims to assess the perceptions of dental undergraduates towards online education, environment and transferable skills and patient care during COVID-19 in India, Nepal, and Sri Lanka.

Materials and Methods: Dental preclinical and clinical undergraduate students from India, Nepal and Sri Lanka were recruited from November 2020 to March 2021 through a 47-item web-based survey consisting of psychometrically valid subscales of Dundee Ready Educational Environment Measure (DREEM) and Transferable Skills Questionnaire. The mean scores of students' perceptions of learning, environment, and patient care skills were compared among preclinical and clinical students of the participating countries.

Results: Of total 930 participants, 44.4\% were from India, 26.1\% from Sri Lanka and 29.5\% responses from Nepal. Sri Lanka reported the highest mean scores across all domains of perception indicative of positive attitude. Clinical students from all participating countries had statistically significantly higher positive perception of transferable skills in patient care as opposed to their preclinical counterparts. On the contrary, perception towards learning was higher among preclinical students as opposed to clinical students. These differences were statistically significant for Nepal and Sri Lanka.

Conclusion: The findings of this study underscore the need to develop and implement effective online dental educational interventions to foster academic growth and essential practical skills without compromising academic rigor and continuity in the dental education curriculum.

Keywords: online learning, dental students, academic environment, educational environment, DREEM questionnaire

\section{Introduction}

The coronavirus disease (COVID-19) remains a global threat, which has grappled several countries with a series of devastating waves. ${ }^{1,2}$ Undoubtedly, this pandemic disrupted almost all sectors of life, including education. Despite the availability of vaccines in many countries, the incidence of confirmed COVID-19 cases is trending upwards. These surging trends have resulted in rapid implementation of social distancing mandates and new norms limiting physical conducts in most of the educational institutes with one being school/college closures. Thus, several educational programs underwent sudden transition from face-to-face instructions to 
virtual or E-learning, which reportedly have posed several challenges in acquiring intended learning outcomes. ${ }^{3}$ Health sciences' disciplines, including medical and dental education, faced the disproportionate disruption, particularly on learning of fine motor skills to provide clinical training. ${ }^{4}$

Dental education is aimed at training undergraduates for effective and safe management of dental patients. Further, the training differs from other graduate programs as the dentists need to acquire a broad level of professional elements, including theoretical knowledge, clinical and interpersonal skills, manual dexterity, and fine motor skills to deliver quality health care through a close proximity with patients. ${ }^{5,6}$ COVID-19 makes it challenging to strike an appropriate balance between the acquisition of desired educational outcomes and preventing virus transmission. ${ }^{7}$ Lockdowns and school/college shutdown imposed during the pandemic helped in curbing the spread, however these have impacted all aspects of training activities with limited or no access to preclinical and clinical learning opportunities for dental students worldwide.

During the pandemic, many dental schools halted inperson courses, clinical practice and migrated to didactic instructions online coupled with restricted hands-on preclinical and clinical learning in small groups. ${ }^{8,9}$ Dental institutions adapted to the "new normal" education system with the integration of video conferencing options to deliver education. The use of online platforms, such as Zoom, Google meet, video demonstrations, and live or stream videos, and pre-recorded lectures are some of the virtual teaching methods adapted by the dental colleges. ${ }^{8}$ Shifting to the online mode of learning during the pandemic was the essential in order to avoid the spread of infection as well as crowding. ${ }^{10}$

Virtual learning poses several advantages, such as transferring knowledge to a large number of recipients, accommodating different learning styles, and shifting passive teacher-centered learning to active learning. ${ }^{11}$ Although online platforms offer theoretical training, their use in practical training may be questionable. Although some disciplines of dentistry can function well with online teaching, others requiring patient interactions have limited opportunities to retain a seamless flow. For instance, in branches where patient care is the main objective, it is required for students to meet the prerequisite of pre-clinical hands-on training prior to the actual clinical work in order to ensure competency in patient management with dental diseases. ${ }^{12}$ Given the advancement and availability of technology, simulation of clinical environments through modalities, including haptics, Virtual reality/Augmented Reality-based simulation devices has been made possible without actually being in a clinical environment. ${ }^{13}$ However, these high-end technological devices are scarce or almost non-existent in resource-strained countries. ${ }^{14}$ According to the recent United Nations Educational, Scientific Cultural Organization (UNESCO) report, lower-middle-income countries (LMICs) spend only $\$ 48$ for each learner as opposed to $\$ 8501$ per individual among high-income countries. ${ }^{15}$ This highlights a huge disparity in per-capita education spending across these countries. ${ }^{15}$ COVID-19 has widened these disparities and has caused a dramatic change in the educational environment. ${ }^{8,9,15}$

Educational environment encompasses the infrastructure, behavior of the teachers, fellow students, and the teaching methodology used. ${ }^{16}$ Educational environment has a considerable impact on the effectiveness of curriculum and educational outcomes, with an increased emphasis on transferable skills in dental education. ${ }^{16,17}$ Successful dental teaching methodology intends to deliver transferable skills, including patient care and critical skills, teamwork, and health promotion. ${ }^{18}$ Pandemic-related lockdowns forced the switch to online teaching in order to continue providing education. Consequently, this mode may have affected the educational environment as well as its outcome, ie, transferable skills. Since the success of these changes largely depends on the perception of students, it is vital to identify students' perceptions on this novel experience of virtual learning during the pandemic. This is highly important in dentistry, given the limited utilization of virtual platforms to provide practical clinical or preclinical training across LMICs. ${ }^{19}$

Previous studies have assessed the learning perception of educational environment and transferable skills among dental students using the DREEM (Dundee Ready Educational Environment Measure) questionnaire and students' perception of transferable skills. ${ }^{18,20,21}$ However, the pandemic situation creates the need to evaluate the learning perceptions and transferable skills of dental students in the virtual classrooms. Furthermore, studies are available on the student's perceptions of different e-learning modalities across various countries; however, little is known about the dental students' perception in the developing countries of South Asia. It is important to compare students' perception of learning across multiple LMICs of South Asia, as undergraduate dental students in this region have comparable resources and learning environments, 
which is significantly different from the developed nations. Therefore, the current study aimed to assess dental students' perception of learning, education environment, skills to deliver patient care, and critical thinking skills gained through online learning platforms in dental education during COVID-19 pandemic across three LMICs, including, India, Nepal and Sri Lanka in the South Asian region.

\section{Materials and Methods Study Design and Setting}

The cross-sectional study was conducted in three countries India, Nepal and Sri Lanka, during the period 17th November 2020 to 17th March 2021. This period corresponds to the time period when online learning mode had been adopted for a minimum of 6 months in each country during the pandemic.

\section{Ethical Considerations}

An ethical approval regarding the conduction of the study was obtained from the respective ethical committees of each participating country (IEC/VSPMDCRC/25/2020, Institutional Ethical Committee Vidya Shikshan Prasarak Mandal Dental College and Research Center, India. ERC/ FDS/UOP/E/2020/39 Ethical Review Committee, Faculty of Dental Sciences, University of Peradeniya, Sri Lanka. 490/077/078-IRC, B.P Koirala Institute of Health Sciences, Nepal). Confidentiality and voluntary consent forms were attached to the questionnaire. A cover letter explaining the purpose of the study was also attached to the survey. It was ensured that no computer Internet Protocol (IP) addresses were collected, and investigators had no way of identifying the participating students.

\section{Sample Recruitment}

A sample of undergraduate dental students was recruited via a convenience sampling method across all three countries utilizing a uniform inclusion criterion: 1. All universities enrolled undergraduate dental students, received dental learning via online mode during the pandemic for at least 6 months; 2. Students, who were willing to participate and provide voluntary informed consent. Students, who were unable to comprehend English and those with no access to the internet were excluded from the study.

\section{Questionnaire and Procedure}

A web-based survey was administered using a 47-item psychometric valid instrument. The survey instrument or questionnaire consisted of three parts. Part one used three subscales of DREEM (Dundee Ready Educational Environment Measure) developed by Roff et al. 1 . Student's perception of learning (12 items), 2. Student's academic self-perception ( 8 items), 3. Student's perception of atmosphere (12 items). ${ }^{22}$ The DREEM questionnaire has been used previously for medical and dental professional programs, and is reported to be neither culture nor context-specific. $^{23-25}$ Moreover, the DREEM has been widely used in evaluation for diagnostic purposes and comparing different groups. ${ }^{26}$ DREEM provides an opportunity to examine the individual items of the overall scale through the mean score obtained for each of the items. This further enables the identification of specific strengths and weaknesses within the educational environment. Each item was measured using a 5-point Likert scale ranging from $0=$ strongly disagree, $1=$ disagree, $2=$ uncertain, $3=$ agree to $4=$ strongly agree. Scores in the first three domains had potential maximum values of 48,32 and 48 , respectively. Domain totals were calculated and transformed to percent score to allow inter-domain comparison. Part 2 of the questionnaire consisted of a domain selected from the perception of transferable skills questionnaire, which was developed by Sun et al. ${ }^{18}$ It is a valid and reliable tool to test students' perception of transferable skill requirements. The domain-patient care and critical skills was selected for use in the present study consisting of 7 items that were scored on a 5-point Likert scale. Overall high scores indicated positive perception towards transferable of skills. The domain subscale reported the Cronbach Alpha value as $0.887 .{ }^{18}$ Part 3 of the questionnaire consisted of the demographics section which included 8 items.

The questionnaire for all three countries was in English, as this was the preferred language of teaching in all participating countries. The questionnaire was electronically distributed with the survey link being accessible online through WhatsApp and other social media platforms by the study investigators. The estimated time to complete the survey was approximately 10 minutes.

\section{Statistical Analysis}

Participants' responses in Qualtrics were first preprocessed or cleaned and then exported to IBM SPSS version 26.0 (IBM Corp. Armonk, NY, USA) for statistical analyses. Incomplete responses and those with invalid data entries were excluded. Mean and standard deviation were used to represent continuous variables. Counts and proportions 
were used to express categorical variables. Inferential analyses were conducted through Pearson correlation, Chisquare tests, Independent samples-t-tests or Welch's $t$-test (if equality of variance was not assumed) and One-way ANOVA. Tukey's post hoc analysis was conducted if any of the mean differences across subgroups were found to be significant through One-way ANOVA. The Normality and Homoscedasticity assumptions were assessed through Shapiro-Wilk test, and F-tests. All the subscales of the survey instrument were subject to reliability analyses through Cronbach's alpha. All analyses were conducted at $\alpha=0.05$. The sample size country was ascertained to detect a very small effect size $(d=0.2)$ at the $95 \%$ confidence interval to have sufficient power. ${ }^{27,28}$ The minimum sample required was 788 . An additional $15 \%$ was added to account for incomplete entries $(788+15 \%$ of 788 =906). We used the Checklist for Statistical Assessment of Medical Papers (CHAMP) statement for reporting our results. $^{29}$

Variables and Measures: For the demographic characteristics, we used variables such as age, gender, year of dental program, the current didactic method, webtools used for lectures and clinical demonstrations. We categorized our sample into preclinical and clinical subgroups depending upon the year of the dental program. For instance, First- and second-year students were preclinical, whereas third- and final-year students were included in the clinical category. The primary outcomes of interest (dependent variables) in this study were mean scores of SPL, SASP, SPA, and PISPC. These mean scores were compared among countries involved in this study.

\section{Results}

A total of 930 valid responses from all the participating countries were included in the final analysis. Of 930, $44.4 \%$ responses were from India alone, and remaining $55.6 \%$ responses were from Nepal and Sri Lanka (Table 1). Overall, the study population was predominantly females, which ranged from $61.3 \%$ to $80.6 \%$ across the participating countries. The highest proportion of the responses were from final-year students, forming a sizable part of the clinical group depending upon the curriculum. Every 5 in 10 Indian and Sri Lankan students reported "Online" didactic method as being predominantly used, while other didactic methods, including "completely in person" and "Hybrid" were the most commonly used in Nepal during the study period (Table 1). In India and Nepal, the lectures were delivered through live sessions, while Sri Lanka used pre-recorded lectures the majority of the time. Moodle was the most frequently used virtual platform in Sri Lanka, while India and Nepal used a combination of virtual platforms for lectures as well as clinical demonstrations (Table 1). The results of the oneway ANOVA indicate significant differences in the mean scores of students' academic self-perception (SASP), students' perception of learning (SPL), students' perception of atmosphere (SPA), and perception of transferable skills of patient care (PTSPC) across countries (Table 2). Among all countries, students from Sri Lanka had the highest mean scores of academic self-perception indicative of a feeling more on the positive side (19.1 \pm 4.4$)$, a more positive perception of learning (28.96 \pm 5.8$)$, and a greater positive perception towards atmosphere (30.2 \pm 6.20 ; Table 2). The results of post-hoc Tukey's test indicate that all scores corresponding to SASP $(p$ value $=0.032)$, SPA $(p$ value $=0.005)$, and PTSPC $(p$ value $=0.02)$ were statistically different among India and Nepal. Similarly, Nepal and Sri Lanka were statistically different in the scores of SASP $(p<0.001)$, SPA $(p<0.001)$, and PTSPC $(\mathrm{p}$ value $=0.001)$.

In India, 138 preclinical and 265 clinical students took the survey. An independent-samples $t$-test was run to determine if there were differences in the perceptions between preclinical and clinical dental students. There were no outliers in the data, as assessed by inspection of a boxplot. Mean perception scores for each level of curriculum (preclinical vs clinical) were normally distributed, as assessed by Shapiro-Wilk's test $(p>0.05)$ and visual inspection of histograms. The clinical students in India had a significantly higher perception of atmosphere than the preclinical students $(\mathrm{M}=29.5, \mathrm{SD}=6.90$ vs $\mathrm{M}=27.6, \mathrm{SD}$ $=8.03 ; \mathrm{p}$ value $=0.02$; Table 3 ). Similarly, PTSPC mean score was higher among clinical students than preclinical students $(\mathrm{M}=17.2, \mathrm{SD}=5.2$ vs $\mathrm{M}=15.8, \mathrm{SD}=5.1 ; \mathrm{p}$ value $=0.01$; Table 3 )

In contrast, preclinical students in Nepal had a higher perception of atmosphere than the clinical students, and the results were marginally significant $(\mathrm{M}=28.0, \mathrm{SD}=6.8$ vs $\mathrm{M}=26.3, \mathrm{SD}=5.8, \mathrm{p}$ value $=0.05$; Table 3 ). Additionally, preclinical students in Nepal reported having a significantly higher perception of learning than clinical students $(\mathrm{M}=25.2, \mathrm{SD}=6.6$ vs $\mathrm{M}=21.6, \mathrm{SD}=7.3 ; \mathrm{p}$ $<0.0001$; Table 3). In Sri Lanka, preclinical students had a significantly higher perception of learning than clinical students $(\mathrm{M}=30.0, \mathrm{SD}=4.7$ vs $\mathrm{M}=28.0, \mathrm{SD}=6.5 ; \mathrm{p}$ value $=0.01$; Table 3 ). The mean PTSPC score was higher 
Table I Demographic Characteristics of the Study Population $(N=930)$

\begin{tabular}{|c|c|c|c|c|c|}
\hline Variables & Groups & All $(\mathbf{N}=930)$ & India $(n=4 \mid 3)$ & Nepal $(n=274)$ & Sri Lanka $(n=243)$ \\
\hline \multirow[t]{2}{*}{ Age (M $\pm S D)$} & \multirow[t]{2}{*}{-} & $23.5 \pm 3.2$ & $22.7 \pm I .5$ & $23.5 \pm 5.3$ & $24.7 \pm I .5$ \\
\hline & & $\mathbf{N}(\%)$ & n (\%) & n (\%) & n (\%) \\
\hline \multirow[t]{2}{*}{ Sex } & Male & $250(26.9)$ & 79 (19.1) & 99 (36.I) & $72(29.6)$ \\
\hline & Female & 669 (7I.9) & $333(80.6)$ & $168(61.3)$ & $168(69.1)$ \\
\hline \multirow[t]{4}{*}{ Dental program year } & First year & $125(13.4)$ & $35(8.5)$ & 31 (1I.3) & $59(24.3)$ \\
\hline & Second year & $238(25.6)$ & $103(24.9)$ & $79(28.8)$ & $56(23.0)$ \\
\hline & Third year & $230(24.7)$ & $125(30.3)$ & $48(17.5)$ & $57(23.5)$ \\
\hline & Final year & $280(30.1)$ & $140(33.9)$ & 71 (25.9) & $69(24.6)$ \\
\hline \multirow[t]{2}{*}{ Curriculum } & Preclinical & $363(39.0)$ & $138(33.4)$ & $110(40.1)$ & $115(47.3)$ \\
\hline & Clinical & $510(54.8)$ & $265(64.2)$ & $119(43.4)$ & $126(5 \mid .9)$ \\
\hline \multirow[t]{3}{*}{ Current didactic method } & Completely in person & $196(21.1)$ & $57(13.8)$ & $|3|(47.8)$ & $8(3.3)$ \\
\hline & Online & $352(37.8)$ & $199(48.2)$ & $20(7.3)$ & I33 (54.7) \\
\hline & Hybrid & $368(39.6)$ & $|5|(36.6)$ & $|2|(44.2)$ & $96(39.5)$ \\
\hline \multirow[t]{3}{*}{ Method of lecture delivery } & Pre-recorded lectures & $236(25.4)$ & $4(1.0)$ & $8(2.9)$ & $224(92.2)$ \\
\hline & Live sessions & $44 \mid(47.4)$ & $300(72.6)$ & $139(50.7)$ & $2(0.8)$ \\
\hline & Both of above & $248(26.7)$ & $108(26.2)$ & $124(45.3)$ & $16(6.6)$ \\
\hline \multirow[t]{5}{*}{ Webtool used for lectures } & Zoom & $112(12.0)$ & $52(12.6)$ & $57(20.8)$ & $3(1.2)$ \\
\hline & Moodle & I6I (I7.3) & I (0.2) & I $(0.4)$ & $159(65.4)$ \\
\hline & Google meet & $96(10.3)$ & $75(18.2)$ & $21(7.7)$ & $0(0.0)$ \\
\hline & Combination of other & $4 I I(44.2)$ & $187(45.3)$ & $143(52.2)$ & 81 (33.3) \\
\hline & Zoom and Google meet & $150(16.1)$ & & & \\
\hline \multirow{5}{*}{$\begin{array}{l}\text { Webtool used for clinical } \\
\text { demonstration }\end{array}$} & Zoom & $156(16.8)$ & $62(15.0)$ & $72(26.3)$ & $22(9.1)$ \\
\hline & Moodle & $133(14.3)$ & $2(0.5)$ & $0(0.0)$ & $|3|(53.9)$ \\
\hline & Google meet & $118(12.7)$ & $79(19.1)$ & $39(14.2)$ & $0(0.0)$ \\
\hline & Zoom and Google meet & $115(12.4)$ & $69(16.7)$ & $46(16.8)$ & $0(0.0)$ \\
\hline & $\begin{array}{l}\text { Combination of other } \\
\text { technology tools }\end{array}$ & $408(43.9)$ & $201(48.7)$ & $117(42.7)$ & $90(37.0)$ \\
\hline
\end{tabular}

Notes: Percentages may not add up to $100 \%$ because of unreported data. Other technology tools include YouTube, WhatsApp, Go to webinar etc. First and second year students: preclinical; third- and fourth-year students: clinical.

Table 2 Cross-Country Comparisons of Perceptions of Online Learning Among All Students

\begin{tabular}{|c|c|c|c|c|c|c|c|c|}
\hline \multirow[t]{2}{*}{ Country } & \multicolumn{2}{|l|}{ SPL } & \multicolumn{2}{|l|}{ SASP } & \multicolumn{2}{|l|}{ SPA } & \multicolumn{2}{|l|}{ PISPC } \\
\hline & $M \pm S D$ & $P$-value & $M \pm S D$ & P-value & $M \pm S D$ & $P$ value & $M \pm S D$ & P-value \\
\hline India & $25.5 \pm 7.1$ & $<0.000 I^{*}$ & $18.2 \pm 5.4$ & $<0.0001 *$ & $28.9 \pm 7.3$ & $<0.000 I^{*}$ & $16.7 \pm 5.2$ & $0.001 *$ \\
\hline Nepal & $23.3 \pm 7.2$ & & $|7| \pm 5.7$. & & $27.1 \pm 6.3$ & & $15.6 \pm 5.4$ & \\
\hline Sri Lanka & $29.0 \pm 5.8$ & & $19.1 \pm 4.4$ & & $30.2 \pm 6.2$ & & $17.3 \pm 4.5$ & \\
\hline
\end{tabular}

Note: $* \mathrm{P}<0.05$ are statistically significant.

Abbreviations: SPL, students' perception of learning; SASP, students' academic self-perception; SPA, students' perception of atmosphere; PTSPC, perceptions of transferable skills of patient care.

among clinical students than preclinical students in Sri Lanka $(M=19.1, S D=3.5$ vs $M=15.3, S D=4.6$; $p<0.0001$; Table 3). Reliability diagnostics of all constructs were performed, and the scale had a high level of internal consistency, as determined by a Cronbach's alpha that ranged from 0.827 to 0.937 overall (Table 4). The lowest yet reasonable Cronbach's alpha values were found for SPA (0.761) and SASP (0.788) in Nepal and Sri Lanka, 
Table 3 Cross-Country Comparisons of Perceptions of Online Learning Among Preclinical and Clinical Subgroups

\begin{tabular}{|c|c|c|c|c|c|c|c|c|c|}
\hline \multirow[t]{2}{*}{ Domain } & \multirow[t]{2}{*}{ Groups } & \multicolumn{2}{|l|}{ Overall } & \multicolumn{2}{|l|}{ India } & \multicolumn{2}{|l|}{ Nepal } & \multicolumn{2}{|c|}{ Sri Lanka } \\
\hline & & $M \pm S D$ & $P$-value & $M \pm S D$ & P-value & $M \pm S D$ & $P$ value & $M \pm S D$ & P-value \\
\hline SPL & $\begin{array}{l}\text { Preclinical } \\
\text { Clinical }\end{array}$ & $\begin{array}{l}26.5 \pm 6.7 \\
25.4 \pm 7.3\end{array}$ & $0.02 *$ & $\begin{array}{l}24.7 \pm 7.2 \\
25.9 \pm 7.0\end{array}$ & 0.1 & $\begin{array}{l}25.2 \pm 6.6 \\
21.6 \pm 7.3\end{array}$ & $<0.000 I^{*}$ & $\begin{array}{l}30.0 \pm 4.7 \\
28.0 \pm 6.5\end{array}$ & $0.01 *$ \\
\hline SASP & $\begin{array}{l}\text { Preclinical } \\
\text { Clinical }\end{array}$ & $\begin{array}{l}18.3 \pm 5.1 \\
18.1 \pm 5.4\end{array}$ & 0.6 & $\begin{array}{l}\mid 8.2 \pm 5.32 \\
|8.3 \pm 5.5|\end{array}$ & 0.9 & $\begin{array}{l}17.2 \pm 5.6 \\
17.1 \pm 5.8\end{array}$ & 0.1 & $\begin{array}{l}19.5 \pm 4.0 \\
18.7 \pm 4.6\end{array}$ & 0.2 \\
\hline SPA & $\begin{array}{l}\text { Preclinical } \\
\text { Clinical }\end{array}$ & $\begin{array}{l}28.7 \pm 7.0 \\
28.8 \pm 6.7\end{array}$ & 0.8 & $\begin{array}{l}27.6 \pm 8.03 \\
29.5 \pm 6.90\end{array}$ & $0.02 *$ & $\begin{array}{l}28.0 \pm 6.8 \\
26.3 \pm 5.8\end{array}$ & $0.05^{* *}$ & $\begin{array}{l}30.6 \pm 5.5 \\
29.8 \pm 6.8\end{array}$ & 0.3 \\
\hline PTSPC & $\begin{array}{l}\text { Preclinical } \\
\text { Clinical }\end{array}$ & $\begin{array}{l}15.4 \pm 4.8 \\
17.4 \pm 5 . \mid\end{array}$ & $<0.001 *$ & $\begin{array}{l}15.8 \pm 5.10 \\
17.2 \pm 5.20\end{array}$ & $0.01 *$ & $\begin{array}{l}15.1 \pm 4.7 \\
16.0 \pm 5.9\end{array}$ & 0.2 & $\begin{array}{l}15.3 \pm 4.6 \\
19.1 \pm 3.5\end{array}$ & $<0.00 I^{*}$ \\
\hline
\end{tabular}

Notes: *Statistically significant. **Marginally significant. First and second year students: preclinical; third- and fourth-year students: clinical.

Abbreviations: SPL, students' perception of learning; SASP, students' academic self-perception; SPA, students' perception of atmosphere; PTSPC, perceptions of transferable skills of patient care; $M$, mean; SD, standard deviation.

respectively (Table 4). Results of Pearson correlation indicated a moderately positive correlation between SPL and PTSPC ( $r=0.43$; Table 5). A similar level of moderate correlation was found between SPA and PTSPC $(r=0.45$; Table 5). A large or strong correlation was found between SPL and SASP $(r=0.67)$, SPL and SPA $(r=0.68)$, SASP and SPA $(r=0.62)$, SASP and PTSPC $(r=0.63)$ (Table 5).

On calculating item-wise mean scores of DREEM constructs, a total of 11 problem areas in Nepal, followed by six in India, and only two problematic areas in Sri Lanka were identified (Table 6). Among all countries, the majority of improvement areas were found in students' perception of learning (SPL) domain. One problem area corresponding to item "the online teaching overemphasizes factual learning" was identified among all participating countries.

\section{Discussion}

The results of the current study indicated that the dental students of India, Sri Lanka and Nepal had an overall positive perception of the educational environment and transferable skills in online education. However, the item-wise analysis indicated several problem areas based on the responses of the students from each country.

Table 4 Reliability Diagnostics

\begin{tabular}{|l|l|l|l|l|}
\hline & Overall Sample & India & Nepal & Sri Lanka \\
\hline Domain (s) & \multicolumn{5}{|l|}{$\mid$} \\
\hline Student perceptions of learning & 0.843 & 0.830 & 0.835 & 0.827 \\
Students' Academic self-perception: & 0.850 & 0.865 & 0.864 & 0.788 \\
Students' Perception of atmosphere & 0.827 & 0.854 & 0.761 & 0.820 \\
Perception of transferable skills in patient care & 0.904 & 0.909 & 0.892 & 0.905 \\
Entire scale & 0.937 & 0.945 & 0.928 & 0.914 \\
\hline
\end{tabular}

Table 5 Correlation Between Constructs of Learning Perceptions and Transferable Skills

\begin{tabular}{|l|l|l|l|l|l|}
\hline Variables & SPL & SASP & SPA & PTSPC & Age (Years) \\
\hline SPL & 1 & $0.673^{* *}$ & $0.685^{* *}$ & $0.434^{* *}$ & 0.019 \\
SASP & & 1 & $0.625^{* *}$ & $0.639 * *$ & -0.014 \\
SPA & & 1 & $0.456^{* *}$ & -0.025 \\
PTSPC & & & 1 & -0.004 \\
\hline
\end{tabular}

Note: ${ }^{* *} p<0.01$.

Abbreviations: SPL, students' perception of learning; SASP, students' academic self-perception; SPA, students' perception of atmosphere; PTSPC, perceptions of transferable skills of patient care. 


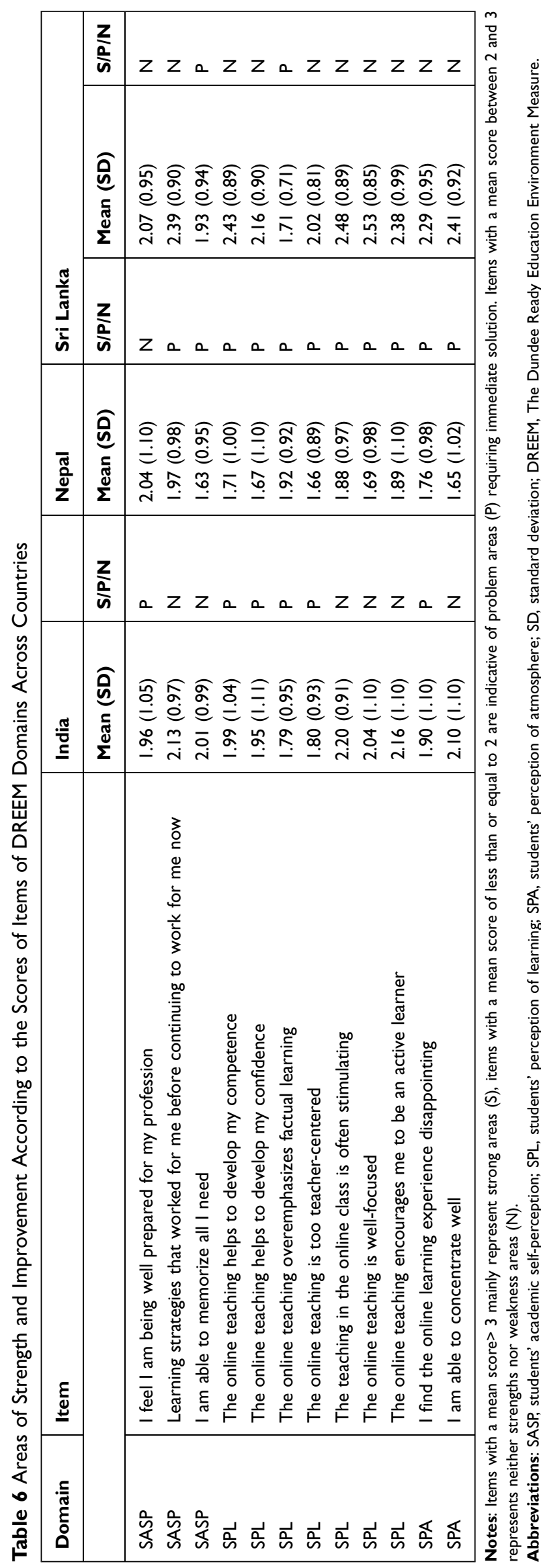


Countries in the South Asian region share comparable resources and learning environments, which are remarkably different from the resources available in high-income or developed nations. ${ }^{15}$ In countries, such as India, Pakistan, Nepal and Sri Lanka, online learning was not a regular part of the teaching curriculum in dental colleges, and it was quickly adopted given the pandemic's rapid progression and its subsequent social distancing mandates. $^{30-33}$ Similar observations were made in other developing countries like Ukraine, where distance learning was successfully implemented; however, the authors raised concerns regarding development of practical clinical skills; while in Iran, medical departments uploaded study material on the university website. ${ }^{34,35}$

The finding of positive perception was consistent with the previous study, that indicated positive perception, acceptability and usability of online mode of learning by the dental students. ${ }^{11}$ Factors such as ease of access with new online tools, flexibility in time and place of access and relaxed environment in internet-based clinical casebased discussions could have contributed to the overall positive perceptions. ${ }^{36,37}$

On comparing the overall mean scores, a statistically significant difference was observed across all domains perceptions of academic self-perception, perception of learning, perception of atmosphere, perception of patient care and critical skills among three countries. Possibly, factors such as year of the training, political, cultural and economic conditions can influence students' perception and attitude of the students towards education. ${ }^{20,38}$ All three countries used different modes of online learning tools. While there are limited data available on the selection of an appropriate online teaching platform in terms of students' behavior, engagement and learning, the use of different modes of online learning could have partly contributed to the cross-country differences found by the current study. ${ }^{39}$

The students' perception of learning, atmosphere and academic self-perception together make essential measures of the educational environment, mean scores of which were found to be highest in students of Sri Lanka. The educational environment can directly or indirectly affect learning, and includes several components, such as rooms for lectures, tutorials and clinical activities, facilitators and barriers of learning, learning opportunities, atmosphere created by fellow students; and faculty including teaching, clinical and administrative staff. ${ }^{16,40}$ This can possibly impact the behavior of students, their approach towards studies, and the educational outcomes, given the wellestablished association between students' perception towards the educational environment and their academic performance. $^{17,20,41,42}$

Another critical component, investigated throughout the study, was transferable skills pertaining to patient care. Transferable skills can be understood as skills that provide support across disciplines, and have the potential to be transferred to various settings within the educational or workplace context. ${ }^{43}$ More recently, Olesen et al highlighted the importance of transferable skills for future healthcare workers to adapt effectively to the evolving condition during practice. ${ }^{44}$ Dental education aims to develop the competency in dental students along six main domains: professionalism, communication and leadership, critical thinking, health promotion, scientific and clinical knowledge, and patient care. ${ }^{45}$ Recently, there has been an increased emphasis on assessing the students' understanding and perception of transferable skills as these are essentials for their overall development and employability. ${ }^{46,47}$ Moreover, previous studies have highlighted the importance of transferable skills in patient care in later years of practice as the practitioner gains more experience, evaluating effectiveness of dental teaching programs and the future practitioners' holistic development. ${ }^{18,47,48}$

Our study found a significant association between transferable skills in patient care and other components of the educational environment (SPL, SASP and SPL). The assessment of perception of the environment will provide an insight into the students' self-perceptions and understanding regarding their perception of transferable skills in critical thinking and patient care. ${ }^{48}$ Consistent with previous reports, the learning environment is an important indicator for ascertaining the effectiveness of curriculum implementation as well as a precursor for the provision of effective learning. ${ }^{41,49,50}$

The results of this study also indicate the impact of dental curriculum type (preclinical vs clinical) on students' perception of learning. The overall comparison of scores indicates that the preclinical students perceived higher learning and academic self-perceptions and lower perceptions with regard to atmosphere and transferable skills. Similar results were obtained by Ansari and Kossioni, who reported second-year students with higher perception scores with significant differences in the domain of SPL. ${ }^{20,51}$ These differences may be attributed to the fact that certain aspects of dental education can be taught more 
easily using online mode compared to others, such as lectures, although the preclinical/simulation/laboratory training and clinical training are more challenging to teach using remote instruction methods. ${ }^{8}$ However, the absence of simulation devices in low resourced countries like India, Nepal and Sri Lanka; and challenges regarding online simulation practical pre-clinical training may have contributed to lower SPA and PTSPC scores in the preclinical group. Additionally, it is easier to impart the theoretical concepts in the earlier years (preclinical) which may be supportive towards the current use of online mode. On the other hand, the use of clinical case discussion and problem-based learning in clinical-based topics using online learning may be of use in various colleges across the three countries, resulting in higher PTSPC scores across the clinical groups.

Further analysis resulted in identification and understanding of the perceptions and problems identified by the students pertinent to individual countries within the framework of the study. Overall, students from India indicated a positive perception in the SPL, SASP and SPA. The combination of the previous academic years' clinical exposure and use of YouTube videos for clinical demonstrations could be responsible for higher scores in all the domains by the clinical group. ${ }^{12}$ With access to the high-speed internet and lack of difficulties encountered by Indian students, effective use of the various online teaching modes in dental colleges could be responsible for giving a positive perception. ${ }^{30}$ In the context of SPL, when the individual items in subscales were analyzed, the students identified many problem areas. This implies the need to modify the teaching content as per online mode of teaching. Teaching methods such as the use of problem-based learning and virtual patient-based learning, use of flipped classrooms/blended learning methods, use of learning management systems, such as Canvas, Examsoft, and Brightspace to conduct examinations remotely and analyze feedbacks from faculty and students for improvement of effectiveness of online learning methods can be taken up by the educational authorities in India for future improvements. $^{14,52}$

The data from Sri Lanka indicated positive perception towards e-learning. The reliance on Moodle platform which enables access to material at a varied pace for all types of learners, can be assumed to be a large contributor. While the mean score of SPL, SASP and SPA were less in clinical subgroup, these observations could be due to lack of clinical training due to the ongoing pandemic. In order to improve the issues regarding online teaching that overemphasize factual learning, it is suggested that investment in user-friendly and versatile online resources may further improve e-learning activities and outcomes. ${ }^{32}$ The results from Sri Lanka initiate thought regarding incorporation of learning resources like case studies, quizzes, discussions through virtual platforms, which may enhance students' learning environment and perception of transferable skills.

The results from Nepal showed the lowest mean scores of SASP, SPL and SPA. When the preclinical and clinical students' perceptions were compared in Nepal, both the preclinical and clinical students perceived SASP, SPA positively; however, the clinical students perceived negatively. Regarding the PTSPC, the clinical students showed higher scores. Increased use of other platforms for clinical demonstrations like YouTube could be responsible for the results obtained. Even though the students showed an overall positive perception, they identified 11 out of 12 items as problem areas. Previous research has pointed at how the students as well as faculty perceived online mode of learning as ineffective or moderate in Nepal. ${ }^{33,53}$ Various challenges in using online learning in Nepal have been pointed out, such as IT infrastructure, faculty's competencies and their training/support, students' access to computer/internet, conducive home environment for elearning, etc. ${ }^{33}$ Future improvement in the faculty skill, incentives and reward for the development and delivery of online content and improved institutional strategies are suggested for better perceptions of online learning in Nepal. $^{54}$

There are only limited studies from India, Sri Lanka \& Nepal in this regard and this research work provides certain lines of continuous quality improvement and innovation that may add towards the quality in the changing world dynamics for the subcontinent. In order to continue effective dental education in pandemic-like situations, future studies on the effectiveness of e-learning solutions in dental education can be performed. Through a combined effort by the countries in the South Asian region with similar resources, efforts should be made in the development of affordable e-learning solutions.

The study has several strengths: firstly, to our knowledge, this is the only study that analyzed the perceptions of dental students across three countries of South Asian region regarding online education during the pandemic, and secondly the perceptions of educational environment using online mode of learning during the pandemic have not been analyzed before. 
However, this study has certain limitations. First, due to the cross-sectional nature of the study, causality could not be inferred. Second, self-reporting bias may have been introduced as it can be driven by the feelings of the respondents at the time of taking the survey. Third, the findings will have limited generalizability as not all universities across the three countries participated in the study. Fourth, other variables related to economic conditions were not collected, which may have contributed to the lower scores of perceptions. Lastly, language bias may have been introduced in the study as the medium of the survey used was English only. In addition, selection bias might have been introduced in the study as only students with internet access were included.

\section{Conclusion}

The dental undergraduate students in India, Nepal and Sri Lanka showed an overall positive perception regarding the educational environment and transferable skills for the online mode of learning during the COVID-19 pandemic, whilst the students in each country identified problem areas that are in the need of attention. Moreover, significant differences in all the domains analyzed were found between all three countries. The highest mean scores in all the domains were reported by dental students in Sri Lanka. The results of the current study can be used to direct developments in delivering online dental education in the future in resource strained countries.

\section{Abbreviations}

UNESCO, United Nations Educational, Scientific Cultural Organization; LMIC, Lower-Middle-Income Countries; DREEM, Dundee Ready Educational Environment Measure; IBM SPSS, International Business Machines Corporation Statistical Package for Social Sciences; ANOVA, Analysis of Variance; SASP, Students' academic self-perception; SPL, Students' perception of learning; PTSPC, Perception of transferable skills of patient care; SPA, Students' perception of atmosphere.

\section{Data Sharing Statement}

Data will be available from the corresponding authors upon request.

\section{Consent for Publication}

All the authors of the manuscript confirm that the details of the manuscript can be published.

\section{Author Contributions}

All authors made substantial contributions to conception and design, acquisition of data, or analysis and interpretation of data; took part in drafting the article or revising it critically for important intellectual content; agreed to submit to the current journal; gave final approval for the version to be published; and agreed to be accountable for all aspects of the work.

\section{Disclosure}

The authors report no conflicts of interest in this work.

\section{References}

1. Kaurani P, Batra K, Hooja H. Psychological impact of Covid -19 lockdown (Phase 2) among Indian general population a cross sectional survey. IJSR. 2020;8(9). doi:10.36106/ijsr/2439876

2. Khan G, Sheek-Hussein M, Alsuwaidi AR, Idris K, Abu-Zidan FM. Novel coronavirus pandemic: a global health threat. Turk $J$ Emerg Med. 2020;20(2):55-62. doi:10.4103/2452-2473.285016

3. Adedoyin OB, Soykan E, COVID-19 pandemic and online learning: the challenges and opportunities. Interact Learn Environ. 2020;(3):113. doi:10.1080/10494820.2020.1813180

4. Galibourg A, Maret D, Monsarrat P, Nasr K. Impact of COVID-19 on dental education: How could pre-clinical training be done at home? $J$ Dent Educ. 2020;84(9):949. doi:10.1002/jdd.12360

5. Alzahrani SB, Alrusayes AA, Aldossary MS. Impact of COVID-19 pandemic on dental education, research, and students. Int $J$ Health Sci Res. 2020;10(6):207-212.

6. Al-Saleh SA, Al-Madi EM, Al-Angari NS, Al-Shehri HA, Shukri MM. Survey of perceived stress-inducing problems among dental students, Saudi Arabia. Saudi Dent J. 2010;22(2):83-88. doi:10.1016/j.sdentj.2010.02.007

7. Holden A, Shaban R, Spallek H. COVID-19 and the dental profession: professional tensions and ethical quandaries. The University of Sydney. Available from: https://www.sydney.edu.au/content/dam/cor porate/documents/sydney-policy-lab/policy-paper_covid-19-and-thedental-profession.pdf. Accessed October 8, 2021.

8. Chang TY, Hong G, Paganelli C, et al. Innovation of dental education during COVID-19 pandemic. $J$ Dent Sci. 2021;16(1):15-20. doi:10.1016/j.jds.2020.07.011.

9. Iyer P, Aziz K, Ojcius DM. Impact of COVID-19 on dental education in the United States. J Dent Educ. 2020;84(6):718-722. doi:10.1002/ jdd. 12163

10. Chavarria-Bolanos D, Gomez-Fernandez A, Dittel-Jimenez C, Montero-Aguilar M. E-learning in dental schools in the times of COVID-19: a review and analysis of an educational resource in times of the COVID-19 pandemic. Odovtos Int J Dent Sci. 2020;22 (3):69-86.

11. Asiry MA. Dental students' perceptions of an online learning. Saudi Dent J. 2017;29(4):167-170. doi:10.1016/j.sdentj.2017.03.005

12. Hattar S, AlHadidi A, Sawair FA, Abd Alraheam I, El-Ma'aita A, Wahab FK. Impact of COVID-19 pandemic on dental education: online experience and practice expectations among dental students at the University of Jordan. BMC Med Educ. 2021;21(1):1-10. doi:10.1186/s12909-021-02584-0

13. Ghai S. Are dental schools adequately preparing dental students to face outbreaks of infectious diseases such as COVID-19? J Dent Educ. 2020;84(6):631-633. doi:10.1002/jdd.12174 
14. Haroon Z, Azad AA, Sharif M, Aslam A, Arshad K, Rafiq S. COVID-19 era: challenges and solutions in dental education. $J$ Coll Physicians Surg Pak. 2020;30(Supp1):S129-S131.

15. En.UNESCO.org [Internet]; [updated February 22, 2021; cited June 12, 2021]. Available from: https://en.unesco.org/news/covid-19-twothirds-poorer-countries-are-cutting-their-education-budgets-timewhen-they-can. Accessed September 30, 2021.

16. Zafar A, Asghar S, Fahim MF. A DREEM based appraisal of educational environment at dental colleges: comparing Pakistan and Turkey. J Pak Dent Assoc. 2020;29(3):135-139. doi:10.25301/JPDA.293.135

17. Vaughan B, Carter A, Macfarlane C, Morrison T. The DREEM, part 1: measurement of the educational environment in an osteopathy teaching program. BMC Med Educ. 2014;14(1):99. doi:10.1186/1472-6920-14-99

18. Sun J, Adegbosin AE, Reher V, Rehbein G, Evans J. Validity and reliability of a self- assessment scale for dental and oral health student's perception of transferable skills in Australia. Eur J Dent Educ. 2020;24(1):42-52. doi:10.1111/eje.12466

19. Van Doren EJ, Lee JE, Breitman LS, Chutinan S, Ohyama H. Students' perceptions on dental education in the wake of the COVID-19 pandemic. J Dent Educ. 2020;1-3. doi:10.1002/jdd.12300

20. Al-Ansari AA, El Tantawi MM. Predicting academic performance of dental students using perception of educational environment. $J$ Dent Educ. 2015;79(3):337-344. doi:10.1002/j.0022-0337.2015.79.3. tb05889.x

21. Ostapczuk MS, Hugger A, de Bruin J, Ritz-Timme S, Rotthoff T. DREEM on, dentists! Students' perceptions of the educational environment in a German dental school as measured by the Dundee Ready Education Environment Measure. Eur J Dent Educ. 2012;16(2):6777. doi:10.1111/j.1600-0579.2011.00720.x

22. Roff S, McAaleer S, Harden R, et al. Development and validation of the Dundee Ready Education Environment Measure (DREEM). Med Teach. 1997;19(4):295-299. doi:10.3109/01421599709034208

23. Soemantri D, Herrera C, Riquelme A. Measuring the educational environment in health professions studies: a systematic review. Med Teach. 2010;32(12):947-952. doi:10.3109/01421591003686229

24. Roff S. The Dundee Ready Educational Environment Measure (DREEM)-a generic instrument for measuring students' perceptions of undergraduate health professions curricula. Med Teach. 2005;27 (4):322-325. doi:10.1080/01421590500151054

25. Zawawi AH, Elzubeir M. Using DREEM to compare graduating students' perceptions of learning environments at medical schools adopting contrasting educational strategies. Med Teach. 2012;34 (Suppl 1):S25-S31. doi:10.3109/0142159X.2012.656747

26. Miles S, Swift L, Leinster SJ. The Dundee Ready Education Environment Measure (DREEM): a review of its adoption and use. Med Teach. 2012;34 (9):e620-34. doi:10.3109/0142159X.2012.668625

27. Cohen J. Statistical Power Analysis for the Behavioral Sciences. 2nd ed. Academic press; 1988. Available from: http://utstat.toronto.edu/ brunner/ oldclass/378f16/readings/CohenPower.pdf. Accessed September 30 , 2021.

28. Faul F, Erdfelder E, Buchner A, Lang AG. Statistical power analyses using $\mathrm{G}^{*}$ Power 3.1: tests for correlation and regression analyses. Behav Res Methods. 2009;41(4):1149-1160. doi:10.3758/BRM.41.4.1149

29. Mansournia MA, Collins GS, Nielsen RO, et al. CHecklist for statistical assessment of medical papers: the CHAMP statement [published online ahead of print, 2021 Jan 29]. Br J Sports Med. 2021:bjsports2020-103651. doi:10.1136/bjsports-2020-103651.

30. Samra RK, Nirola A, Verma A, Nagpal A, Thakur M. Dental students' perception on the impact of E-learning in continuing dental education during the current pandemic scenario. Indian J Dent Sci. 2021;13(2):61-72. doi:10.4103/ijds.ijds_14_21

31. Sarwar H, Akhtar H, Naeem MM, et al. Self-reported effectiveness of e-learning classes during COVID-19 pandemic: a nation-wide survey of Pakistani undergraduate dentistry students. Eur J Dent. 2020;14(S 01): S34-S43. PMID: 33003240; PMCID: PMC7775214. doi:10.1055/s0040-1717000
32. Jayasinghe Rasika M, Thilakumara IP, Leuke Bandara D, et al. Sri Lankan dental students' perspective on the effectiveness of e-learning. Asia Pac Scholar. 2022;7:1-10.

33. Shrestha RM, Shrestha S, Acharya A, Gupta A. Online education status at dental colleges during COVID-19 pandemic in Nepal. Kathmandu Univ Med J. 2020;18(2):15-20. PMID: 33605233. doi:10.3126/kumj.v18i2.32939

34. Loban G, Faustova M, Ananieva M, Kostenco V. Covid- 19: the time for reconsidering and improving online learning in the context of medical education in Ukraine. Fundam Appl Res. 2020;38(2):139143. doi:10.33531/farplss.2020.2.25

35. Aghakhani K, Shalbafan M. What COVID-19 outbreak in Iran teaches us about virtual medical education. Med Educ Online. 2020;25 (1):1770567. doi:10.1080/10872981.2020.1770567

36. Martin N, Lazalde OM, Stokes C, Romano D. An evaluation of remote communication versus face-to-face in clinical dental education. $\quad B r$ Dent J. 2012;212(6):277-282. PMID: 22446272. doi:10.1038/sj.bdj.2012.226

37. Edgren G, Haffling AC, Jakobsson U, McAleer S, Danielsen N. Comparing the educational environment (as measured by DREEM) at two different stages of curriculum reform. Med Teach. 2010;32(6): e233-e238. doi:10.3109/01421591003706282

38. Alshare K, Al-Dwairi M, Akour I. Student-instructor perception of computer technologies in developing countries: the case of Jordan. $J$ Comp Inform Syst. 2003;43(4):115-123.

39. Wang K, Zhang L, Ye L. A nationwide survey of online teaching strategies in dental education in China. J Dent Educ. 2021;85(2):128134. doi:10.1002/jdd.12413

40. Schönrock-Adema J, Bouwkamp-Timmer T, van Hell EA, CohenSchotanus J. Key elements in assessing the educational environment: where is the theory? Adv Health Sci Educ. 2012;17(5):727-742. doi:10.1007/s10459-011-9346-8

41. Genn J. AMEE Medical Education Guide No. 23 (Part 1): curriculum, environment, climate, quality and change in medical education -a unifying perspective. Med Teach. 2001;23(4):337-344. doi:10.1080/01421590120063330

42. Genn J. AMEE Medical Education Guide No. 23 (Part 2): curriculum, environment, climate, quality and change in medical education-a unifying perspective. Med Teach. 2001;23(5):445-454.

43. Bennett N, Dunne E, Carre C. Patterns of core and generic skill provision in higher education. High Educ. 1999;37(1):71-93. doi:10.1023/A:1003451727126

44. Olesen KB, Christensen MK, O’Neill LD. What do we mean by "transferable skills"? A literature review of how the concept is conceptualized in undergraduate health sciences education. High Educ Ski Work Based Learn. 2021;11(3):616-634. doi:10.1108/HESWBL01-2020-0012

45. Australian Dental Council. Professional competencies of the newly qualified dentist. Melbourne, Australia: ADC; 2016. Professional Competencies of the Newly Qualified Dental Prosthetist_rebranded. pdf. Available from: adc.org.au. Accessed January 12, 2021.

46. Whitney EM, Walton JN, Aleksejuniene J, Schönwetter DJ. Graduating dental students' views of competency statements: importance, confidence, and time trends from 2008 to 2012. J Dent Educ. 2015;79(3):322-330. doi:10.1002/j.0022-0337.2015.79.3.tb05887.x

47. Evans J, Henderson AJ, Sun J, et al. The value of inter-professional education: a comparative study of dental technology students' perceptions across four countries. Br Dent J. 2015;218(8):481-487. doi:10.1038/sj.bdj.2015.296

48. Bye D, Pushkar D, Conway M. Motivation, interest, and positive affect in traditional and nontraditional undergraduate students. Adult Educ Q. 2007;57(2):141-15. doi:10.1177/0741713606294235

49. Bassaw B, Roff S, McAleer S, et al. Students' perspectives on the educational environment, Faculty of Medical Sciences, Trinidad. Med Teach. 2003;25(5):522-526. doi:10.1080/0142159031000137409 
50. Noreen K, Khan KA, Nehra RA. Students' perception of learning environment using Dundee Ready Education Environment Measure (Dreem) inventory. Pak J Public Health. 2018;8(2):112-116. doi:10.32413/pjph.v8i2.154

51. Kossioni AE, Varela R, Ekonomu I, Lyrakos G, Dimoliatis ID. Students' perceptions of the educational environment in a Greek Dental School, as measured by DREEM. Eur J Dent Educ. 2012;16 (1):e73-e78. doi:10.1111/j.1600-0579.2011.00678.x

52. Nimavat N, Singh S, Fichadiya N, et al. Online medical education in India - different challenges and probable solutions in the age of COVID-19. Adv Med Educ Pract. 2021;12:237-243. doi:10.2147/ AMEP.S295728
53. Tuladhar S, Pradhan D, Parajuli U, Manandhar P, Subedi N. Study on the effectiveness of online classes for undergraduate medical and dental students of Gandaki medical college during COVID 19 pandemic period in Nepal. Orthod J Nepal. 2020;10(2):36-40. doi:10.3126/ojn.v10i2.31146

54. O'Doherty D, Dromey M, Lougheed J, Hannigan A, Last J, McGrath D. Barriers and solutions to online learning in medical education - an integrative review. BMC Med Educ. 2018;18(1):130. doi:10.1186/ s12909-018-1240-0

\section{Publish your work in this journal}

Advances in Medical Education and Practice is an international, peerreviewed, open access journal that aims to present and publish research on Medical Education covering medical, dental, nursing and allied health care professional education. The journal covers undergraduate education, postgraduate training and continuing medical education including emerging trends and innovative models linking education, research, and health care services. The manuscript management system is completely online and includes a very quick and fair peer-review system. Visit http://www.dovepress.com/testimonials.php to read real quotes from published authors. 